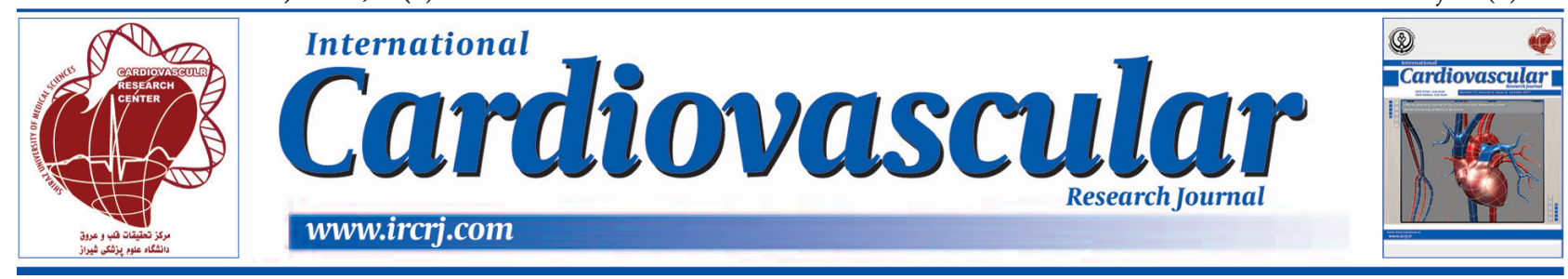

\title{
Dietary Quality after Diagnosis of Coronary Heart Disease
}

\author{
Unal Ozturk ${ }^{1}$, Onder Ozturk ${ }^{2, *}$, Perran Toksoz ${ }^{3}$
}

${ }^{1}$ Dicle University Medicine Faculty, Department of Public Health and Neurology, Diyarbakir, Turkey

${ }^{2}$ Diyarbakır Education and Research Hospital, Department of Cardiology, Diyarbakir, Turkey

${ }^{3}$ Dicle University Medicine Faculty, Department of Public Health, Diyarbakir, Turkey

\begin{tabular}{l}
\hline A R T I C L E I N F O \\
\hline Article Type: \\
Research Article \\
\hline
\end{tabular}

Article History:

Received: 11 Jan 2015

Revised: 23 Jun 2015

Accepted: 19 Aug 2015

\section{Keywords:}

Diet Therapy

Coronary Disease

Nutrition

\begin{abstract}
A B S T R A C T
Background: Dietary saturated fat and cholesterol are the cause of atherosclerosis and cardiovascular disease.

Objectives: This study aimed to assess diet quality after diagnosis of Coronary Heart Disease (CHD).

Patients and Methods: This descriptive study was performed on 242 patients with diagnosis of acute coronary syndrome admitted to a coronary care unit in a cardiology clinic between December 2005 and December 2006. The study questionnaire, including questions about personal information such as age, sex, and education level, was completed by face-to-face interview. Additionally, Diet Quality Index (DQI) was used to assess the subjects' nutritonal status. Then, one-way ANOVA and chi-square tests were used where appropriated to compare the study groups. Besides, linear regression models were used to assess the associations between DQI score and the patients' sociodemographic characteristics and lifestyle factors. P value $\leq 0.05$ was considered to be statistically significant.

Results: The patients' ages ranged from 26 to 85 years and $68.5 \%$ of the patients were male. Considering DQI scoring, $22.7 \%, 75.2 \%$, and $2.1 \%$ of the patients got "inadequate/ low", "average", and "acceptable/high" DQI, respectively. In addition, $28 \%$ of the patients consumed $40 \%$ of calories from total fat, while $55 \%$ consumed $30-40 \%$ of calories from total fat. Also, nearly $30 \%$ of the patients consumed greater than $13 \%$ of calories from saturated fat, while $64 \%$ consumed $10-13 \%$ of calories from saturated fat.

Conclusions: In this study, most of the CHD patients got low DQI scores. In general, $\mathrm{CHD}$ can be prevented. However, if precautions regarding lifestyle modification are not followed, CHD is expected to progress.
\end{abstract}

Implication for health policy/practice/research/medical education:

Dietary factors are important coronary risk factors. However, compliance with dietary recommendations has remained a major problem. Diet quality index is very useful parameter in assessment of dietary pattern in patients with coronary heart disease.

\section{Background}

Coronary Heart Disease (CHD) is a major cause of morbidity, mortality, and economic burden in both developed and developing countries. The risk factors of Cardiovascular Disease (CVD) include hypertension, genetic factors, smoking, diabetes, obesity, physical inactivity, and dyslipidemia (1). Secondary prevention programs, with a focus on risk factors management, have been shown to play a pivotal role in treatment and

*Corresponding author: Onder Ozturk, Diyarbakir Gazi Yasargil Education and Research Hospital, Department of Cardiology, Diyarbakir, Turkey. Tel: +90-5332652602,

E-mail: droozturk21@hotmail.com management of the individuals affected by CHD (2). Efforts at secondary prevention of CHD also have substantial public health implications. In addition to effective cardiac medications, lifestyle modifications have been shown to reduce the risk of future cardiac events (3-5).

Studies found that increased serum Low Density Lipoprotein (LDL)-colesterol level was associated with CHD. These findings led to the diet-heart hypothesis. Diet heart hypothesis was based primarily on the observation of a strong, positive association between saturated fat consumption (essentially animal products) and CHD mortality and morbidity. Saturated fat and cholesterol intake, 
known to increase blood cholesterol, was also positively correlated to the incidence of CHD. It was, therefore, hypothesized that reduction of blood cholesterol level by dietary (or non-dietary, i.e. pharmacological) means might reduce the frequency of cardiac relapses after a first coronary event. Historically, research on the relationship between diet and CVD or mortality focused on single food items or nutrients. More recently, however, the focus has shifted toward markers of overall diet quality and dietary patterns to reflect the multidimensional nature of diets consumed in the population. Diet quality is a major modifiable risk factor well established in prevention of CVD and mortality. Therefore, the relationship between diet and CHD has been studied intensively. Studies on diet quality and CHD have focused largely on determining the dietary risk factors of CHD (612). Accordingly, dietary risk factors for CVD are diets high in saturated and trans fat and low in polyunsaturated fatty acids, vegetables, fruits, and fiber (13-20).

\section{Objectives}

The present study aims to assess diet quality after diagnosis of CHD.

\section{Patients and Methods}

\subsection{Subjects}

This descriptive study was conducted on 242 consecutive patients (166 males and 76 females) admitted to coronary care unit of a cardiology clinic between December 2005 and December 2006 with diagnosis of acute coronary syndrome, defined as (1) Creatine Kinase (CK) $\geq 210 \mathrm{IU} / \mathrm{L}$ and CK-MB $\geq 20 \mathrm{IU} / \mathrm{L}$, or Troponin $\mathrm{T}>0.01 \mathrm{ng} / \mathrm{mL}$, (2) electrocardiographic evidence of ischemia (ST segment deviation $\geq 0.05 \mathrm{mV}$, ST depression $>1 \mathrm{~mm}$, or T-wave inversion $\geq 0.3 \mathrm{mV}$ ), or (3) typical chest pain. The inclusion criteria of the study were aging 18 years and above and suffering from CHD. The study protocol was approved by the Ethics Committee of our department. Besides, written informed consents were obtained from all the patients.

\subsection{Assessment of the Patients' Characteristics}

The data regarding the patients' characteristics were collected by a self-administered questionnaire at the baseline clinical visit after diagnosis of CHD. The patients' characteristics have been summarized in Table 1. Smoking status and physical activity status were collected at 1 year using "yes/no" questions. Smoking status was asked using the following question: "In the last 1 year, have you smoked any cigarettes, cigars, pipes, or other tobacco products". Also, the following question was used to determine the participants' physical activity status: "In the last 1 year, have you exercised for at least 20 minutes on one occasion without stopping".

\subsection{Assessment of Body Weight}

Body weight and height were measured using standard methodology (21). Relative mass was expressed as Body Mass Index (BMI) calculated as kg/m2.

\subsection{Diet Quality Assessment}

Dietary data were collected by Diet Quality Index (DQI), a self-administered food frequency questionnaire, administered by interviewers in the hospital. The DQI reflects 10 dietary characteristics $(22,23)$ and each of the 10 components contributes 10 points to the total DQI score. In this study, the scores were limited to a range of 0 to 10 points. To improve interpretability, scale scoring was changed to reflect a total possible 100 point score, with lower scores reflecting poorer achievement of dietary recommendations and higher scores reflecting better diet quality.

The first 3 components of the DQI reflect macronutrient distribution recommendations; for example, to restrict relative dietary fat to less than or equal to $30 \%$ of energy, to

\begin{tabular}{|c|c|c|c|c|c|c|}
\hline \multirow[t]{2}{*}{ Baseline Characteristics } & \multicolumn{2}{|c|}{ Male $(n=166)$} & \multicolumn{2}{|c|}{ Female $(n=76)$} & \multicolumn{2}{|c|}{ Total $(n=242)$} \\
\hline & Number & $\%$ & Number & $\%$ & & \\
\hline Age (years) $($ mean $\pm S D)$ & $57 \pm 11$ & & $67 \pm 10$ & & $60 \pm 12$ & \\
\hline \multicolumn{7}{|l|}{ Marital status } \\
\hline Married & 165 & 99.4 & 68 & 89.5 & 233 & 96 \\
\hline Widowed & 1 & 0.6 & 8 & 10.5 & 9 & 4 \\
\hline \multicolumn{7}{|l|}{ Education level } \\
\hline Illiterate & 32 & 19.3 & 63 & 82.9 & 95 & 39 \\
\hline Literate & 11 & 6.6 & 5 & 6.6 & 16 & 7 \\
\hline Primary school & 71 & 42.8 & 6 & 7.9 & 77 & 32 \\
\hline Middle school & 34 & 20.5 & 0 & 0.0 & 34 & 14 \\
\hline High school & 12 & 7.2 & 1 & 1.3 & 13 & 5 \\
\hline Academic & 6 & 3.6 & 1 & 1.3 & 7 & 3 \\
\hline \multicolumn{7}{|l|}{ BMI $(\mathrm{kg} / \mathrm{m} 2)$ category } \\
\hline Normal $(<25)$ & 76 & 46.0 & 18 & 24.0 & 94 & 39 \\
\hline Overweight (25 - 29.9) & 73 & 44.0 & 34 & 45.0 & 107 & 44 \\
\hline Obese $(\geq 30)$ & 17 & 10.0 & 24 & 31.0 & 41 & 17 \\
\hline \multicolumn{7}{|l|}{ Physical activity } \\
\hline No & 111 & 66.9 & 73 & 96.0 & 184 & 76 \\
\hline Yes & 55 & 33.1 & 3 & 4.0 & 58 & 24 \\
\hline Smoking in the last 1 year & 85 & 51 & 2 & 2.0 & 87 & 35 \\
\hline
\end{tabular}

Abbreviations: BMI, body mass index 
restrict saturated fat to less than or equal to $10 \%$ of energy, and to consume less than $300 \mathrm{mg}$ dietary cholesterol daily. The next 3 DQI components measure relative differences in consumption of servings of fruits, vegetables, and grains. DQI measures of grain, vegetable, and fruit intake adequacy are adjusted to reflect intake as a proportion of the number of servings recommended for the appropriate energy intake level. The next $2 \mathrm{DQI}$ indicators reflect relative intakes of calcium and iron. The final 2 components of the DQI are 2 new scores designed to measure the constructs of diversity and moderation. The dietary diversity score reflects a weighted average of scores for each of the 4 primary food groups. Each of the 4 broad food categories receives a maximum diversity score of 2.5 out of the 10 possible points. Each component of the dietary moderation score also provides 2.5 of the 10 possible points of the total moderation score.

\subsection{Statistical Analysis}

All data analyses were performed by the SPSS statistical software (version 11.0; Chicago, IL, USA). DQI groups were created to represent inadequate/low (0 - 50 points), average (51 - 80 points), and acceptable/high DQI (81 - 100 points). The participants' characteristics and nutritional variables were summarized using mean and standard deviation for continuous variables and number and percent for categorical ones. In addition, one-way ANOVA and chisquare tests were used where appropriated to compare the study groups. Linear regression models were also used to assess the associations between DQI score and the patients' sociodemographic characteristics and lifestyle factors. Statistical power was 0.85 and $\mathrm{P} \leq 0.05$ was considered to be statistically significant.

\section{Results}

In this study, the patients were between 26 and 85 years old, with the mean age of $60 \pm 12$ years. Besides, $68.5 \%$ of the patients were male, while $31.5 \%$ were female. Only $2.9 \%$ of the patients had education levels beyond high school. Moreover, $17 \%$ of the patients were obese with the mean BMI of $33.9 \pm 3.6 \mathrm{~kg} / \mathrm{m} 2$. Additionally, nearly $35 \%$ of the patients reported smoking and $23 \%$ reported having performed at least one 20-minute session of continued exercise in the past one year (Table 1).

According to the results, $28 \%$ of the patients consumed $40 \%$ of calories from total fat, while $55 \%$ consumed 30 - $40 \%$ of calories from total fat. Besides, about $30 \%$ of the patients consumed greater than $13 \%$ of calories from saturated fat, while $64 \%$ consumed 10 - 13\% of calories from saturated fat. Moreover, $33 \%$ of the patients consumed lower than $300 \mathrm{mg} /$ day dietary cholesterol. Also, 72\% of the patients consumed adequate fruits and vegetables daily, and $85 \%$ consumed $2400-3400 \mathrm{mg}$ /day of salt. This daily salt intake was a little higher and correction was required.

Considering DQI, the results showed that $22.7 \%, 75.2 \%$, and $2.1 \%$ of the patients had inadequate/low ( $0-50$ points), average (51 - 80 points), and acceptable/high DQI (81 100 points), respectively (Table 2, one-way ANOVA). The mean DQI score of the patients was $59.8 \pm 11.7$. The results of multivariat linear regression model for DQI have been presented in Table 3. Accordingly, low diet quality was associated with smoking in the previous one year, lower education level, and obesity.

\section{Discussion}

To date, dietary research and guidance have been focused on dietary patterns rather than on single nutrients or food groups, because dietary components are consumed in combination and are correlated to one another (24). Previous studies showed that lower intakes of saturated and trans fatty acids and higher intakes of unsaturated fatty acids, dietary fiber, and vegetable proteins could reduce the risk of some types of CVD, particularly CHD (2528). Consumption of three or more servings of fruits and vegetables per day compared to less than once per day was also associated with a $27 \%$ reduction in the risk of CVD (29). This was consistent with the results of other studies, indicating a graded risk reduction associated with higher intakes of fruits and vegetables $(25,27)$. It was suggested that dietary intake of green leafy vegetables and foods rich in carotenoids and vitamin $\mathrm{C}$ particularly contributed to this relationship. In most of the above mentioned researches, consumption of vegetables and fruits more than once a week was compared to not eating vegetables and fruits in

\begin{tabular}{|c|c|c|c|c|c|c|}
\hline \multirow{3}{*}{ Gender } & \multicolumn{6}{|c|}{ DQI Score } \\
\hline & \multicolumn{2}{|c|}{0 - 50 Points (Inadequate/Low) } & \multicolumn{2}{|c|}{51 - 80 Points (Average) } & \multicolumn{2}{|c|}{81 - 100 Points (Acceptable/High) } \\
\hline & Number & $\%$ & Number & $\%$ & Number & $\%$ \\
\hline Male & 33 & 19.9 & 129 & 77.7 & 4 & 2.4 \\
\hline Female & 22 & 28.9 & 53 & 69.7 & 1 & 1.3 \\
\hline Total & 55 & 22.7 & 182 & 75.2 & 5 & 2.1 \\
\hline
\end{tabular}

Abbreviations: DQI, diet quality index

$\mathrm{X}^{2}=2.629, \mathrm{P}>0.05$

\begin{tabular}{llll}
\hline \multicolumn{2}{l}{ Table 3. Multivariate Linear Regression Model for the Diet Quality Index } & & \\
\hline Independent Variables & Coefficient & Standard Error & P value \\
\hline Smoking for least 3 months in the last 1 year & -4566 & 1.587 & $<0.05$ \\
Education levels higher than high school & 3.203 & 1.48 & $<0.05$ \\
Obesity (BMI $\geq \mathbf{3 0}$ kg/m2) & -3.354 & 0.756 & $<0.05$ \\
\hline
\end{tabular}

Abbreviations: BMI, body mass index 
a week (25).

DQI is a composite measure of diet quality created to evaluate healthfulness of diets. The major finding of our study was the poor quality of diet among the patients diagnosed with CHD. Our study also showed that diet was associated with CHD, which is consistent with the findings of the previously published reports in the literature $(30,31)$.

In the present study, overall low quality of diet, as determined by a low DQI score, was associated with current smoking, higher BMI, and lower education level. Consistently, a recent population-based study in Brazil (32) found that dietary quality, measured by the healthy eating index, was inversely associated with smoking and BMI. Using the data from the Behavioral Risk Factor Surveillance System, Rafferty and colleagues (33) also found that dietary quality was related to education level. Other studies found similar results, as well. Shea et al. (31) demonstrated that saturated fat and cholesterol intakes, as expressed in the cholesterol-saturated fat index, were inversely related to educational attainment. This might be due to the fact that participants with low education levels might require specific interventional tools to improve dietary quality. Thus, it is particularly important to consider the issues related to health literacy $(34,35)$ and make sure patients can understand the provided materials.

In the current study, the mean score of DQI $(59.8 \pm 11.7)$ was low in the study population. This highlighted the low quality of the patients' current diet and the need for increasing surveillance and lifestyle recommendations by physicians and health professionals to decrease the risk of future CHD events for patients with established CHD. It should also be noted that only a quarter of our patients had acceptable physical activity in the last one year before their coronary events.

The Lyon Diet Heart Study was the first clinical trial supporting the Mediterranean diet, which includes high intake of fruits, vegetables, nuts, legumes, and grains (36). Other recent studies have also supported the Mediterranean diet's protective effects on prevention of CHD (37-39). These studies showed that vegetable and fruit consumption was inversely associated with the risk of ischemic heart disease. Overall, daily consumption of vegetables and fruits is recommended, reflecting the current dietary guidelines.

Dietary recommendations are designed to promote good overall health and reduce the risk of major chronic diseases in the general population. Up to now, most studies on diet and CVD have focused on dietary lipids. Metabolic studies have revealed the detrimental effects of trans fat on the inflammatory factors associated with CHD (1). Until as recently as the 1990 s, the focus of public health recommendations, including the USDA food guide pyramid, was on restricting the intake of total (and particularly saturated) dietary fat to reduce the risk of CVD (40). Based on the most recent evidence, the 2006 American Heart Association (AHA) diet and lifestyle recommendations for CVD risk reduction relaxed guidelines for total fat intake and, rather, made recommendations for each type of fat. Specifically, the AHA now recommends limiting intake of saturated fat to $<7 \%$ and trans fat to $<1 \%$ of energy (27).

\subsection{Conclusion}

In conclusion, the present study results revealed that the quality of diets was poor among the patients with a recent CHD event. CHD can be prevented, but compliance with dietary recommendations remains a major problem. In our view, diet assessment is best done with food records and the most effective way to change dietary intake is to alter the food supply by providing specific foods or supplements or to provide consumers with prepared meals.

\subsection{Study Limitations}

One of the limitations of the present study was the broad classification of smokers. Any amount of smoking in the past 3 months was considered to be smoking, which included both social and occasional smokers. A similar limitation also applies to physical activity measures.

\section{Acknowledgements}

There is no acknowledgement.

\section{Authors' Contribution}

Ozturk U, Ozturk U, and Toksoz P were responsible for 1study concept and design, 2- acquisition of data, 3- analysis and interpretation of data, 4- drafting of the manuscript, 5critical revision of the manuscript for important intellectual content, 6- statistical analysis, 7- administrative, technical, and material support, and 8- study supervision

\section{Financial disclosure}

There is no financial disclosure.

\section{Funding/Support}

There is no funding/support.

\section{References}

1. Ma Y, Li W, Olendzki BC, Pagoto SL, Merriam PA, Chiriboga DE, et al. Dietary quality 1 year after diagnosis of coronary heart disease. $J$ Am Diet Assoc. 2008;108(2):240-6; discussion 6-7.

2. Turkstra E, Hawkes AL, Oldenburg B, Scuffham PA. Costeffectiveness of a coronary heart disease secondary prevention program in patients with myocardial infarction: results from a randomised controlled trial (ProActive Heart). BMC Cardiovasc Disord. 2013;13:33.

3. Blazing MA, O'Connor CM. Evidence supporting secondary prevention strategies. Curr Opin Cardiol. 1999;14(4):303-9.

4. Daubenmier JJ, Weidner G, Sumner MD, Mendell N, Merritt-Worden $\mathrm{T}$, Studley J, et al. The contribution of changes in diet, exercise, and stress management to changes in coronary risk in women and men in the multisite cardiac lifestyle intervention program. Ann Behav Med. 2007;33(1):57-68

5. Ockene I, Ockene J. Helping patients to reduce their risk for coronary heart disease: an overview. Prevention of Coronary Heart Disease Boston, MA: Little, Brown and Company. 1992:173-99.

6. Dauchet L, Amouyel P, Hercberg S, Dallongeville J. Fruit and vegetable consumption and risk of coronary heart disease: a metaanalysis of cohort studies. J Nutr. 2006;136(10):2588-93.

7. Dawber TR, Nickerson RJ, Brand FN, Pool J. Eggs, serum cholesterol, and coronary heart disease. Am J Clin Nutr. 1982;36(4):617-25.

8. Grundy SM, Bilheimer D, Blackburn H, Brown WV, Kwiterovich PO, Jr., Mattson F, et al. Rationale of the diet-heart statement of the American Heart Association. Report of Nutrition Committee. Circulation. 1982;65(4):839A-54A.

9. Harper CR, Jacobson TA. Usefulness of omega-3 fatty acids and the prevention of coronary heart disease. Am J Cardiol. 2005;96(11):1521-9.

10. LaRosa JC, Hunninghake D, Bush D, Criqui MH, Getz GS, Gotto AM, Jr., et al. The cholesterol facts. A summary of the evidence 
relating dietary fats, serum cholesterol, and coronary heart disease. A joint statement by the American Heart Association and the National Heart, Lung, and Blood Institute. The Task Force on Cholesterol Issues, American Heart Association. Circulation. 1990;81(5):1721-33.

11. Nelson GJ. Dietary fat, trans fatty acids, and risk of coronary heart disease. Nutr Rev. 1998;56(8):250-2.

12. Pereira MA, O'Reilly E, Augustsson K, Fraser GE, Goldbourt $\mathrm{U}$, Heitmann BL, et al. Dietary fiber and risk of coronary heart disease: a pooled analysis of cohort studies. Arch Intern Med. 2004;164(4):370-6.

13. Browning LM, Jebb SA. Nutritional influences on inflammation and type 2 diabetes risk. Diabetes Technol Ther. 2006;8(1):45-54.

14. Engler MM, Engler MB. Omega-3 fatty acids: role in cardiovascular health and disease. J Cardiovasc Nurs. 2006;21(1):17-24, quiz 5-6.

15. Erkkila AT, Lichtenstein AH. Fiber and cardiovascular disease risk: how strong is the evidence? J Cardiovasc Nurs. 2006;21(1):3-8.

16. King DE. Dietary fiber, inflammation, and cardiovascular disease. Mol Nutr Food Res. 2005;49(6):594-600.

17. Ma Y, Griffith JA, Chasan-Taber L, Olendzki BC, Jackson E, Stanek EJ, 3rd, et al. Association between dietary fiber and serum C-reactive protein. Am J Clin Nutr. 2006;83(4):760-6.

18. Mozaffarian D. Trans fatty acids - effects on systemic inflammation and endothelial function. Atheroscler Suppl. 2006;7(2):29-32.

19. Olendzki B, Speed C, Domino FJ. Nutritional assessment and counseling for prevention and treatment of cardiovascular disease. Am Fam Physician. 2006;73(2):257-64.

20. Perez-Jimenez F, Lopez-Miranda J, Mata P. Protective effect of dietary monounsaturated fat on arteriosclerosis: beyond cholesterol. Atherosclerosis. 2002;163(2):385-98.

21. Cogill B. Anthropometric indicators measurement guide. 2003.

22. Newby PK, Hu FB, Rimm EB, Smith-Warner SA, Feskanich D, Sampson L, et al. Reproducibility and validity of the Diet Quality Index Revised as assessed by use of a food-frequency questionnaire. Am J Clin Nutr. 2003;78(5):941-9.

23. Patterson RE, Haines PS, Popkin BM. Diet quality index: capturing a multidimensional behavior. J Am Diet Assoc. 1994;94(1):57-64.

24. Najafi M, Sheikhvatan M. Gender differences in coronary artery disease: correlational study on dietary pattern and known cardiovascular risk factors. International cardiovascular research journal. 2013;7(4):124.

25. Amani R, Noorizadeh M, Rahmanian S, Afzali N, Haghighizadeh $\mathrm{MH}$. Nutritional related cardiovascular risk factors in patients with coronary artery disease in Iran: a case-control study. Nutr J. 2010;9:70.

26. Howard BV, Van Horn L, Hsia J, Manson JE, Stefanick ML, Wassertheil-Smoller S, et al. Low-fat dietary pattern and risk of cardiovascular disease: the Women's Health Initiative Randomized Controlled Dietary Modification Trial. JAMA. 2006;295(6):655-66.

27. Lichtenstein AH, Appel LJ, Brands M, Carnethon M, Daniels S,
Franch HA, et al. Diet and lifestyle recommendations revision 2006 A scientific statement from the American Heart Association nutrition committee. Circulation. 2006;114(1):82-96.

28. Lloyd-Jones D, Adams R, Carnethon M, De Simone G, Ferguson TB, Flegal K, et al. Heart disease and stroke statistics--2009 update: a report from the American Heart Association Statistics Committee and Stroke Statistics Subcommittee. Circulation. 2009;119(3):480-6.

29. Hu FB, Willett WC. Optimal diets for prevention of coronary heart disease. JAMA. 2002;288(20):2569-78.

30. McCullough ML, Feskanich D, Stampfer MJ, Giovannucci EL, Rimm EB, Hu FB, et al. Diet quality and major chronic disease risk in men and women: moving toward improved dietary guidance. $\mathrm{Am}$ J Clin Nutr. 2002;76(6):1261-71.

31. Shea S, Melnik TA, Stein AD, Zansky SM, Maylahn C, Basch CE. Age, sex, educational attainment, and race/ethnicity in relation to consumption of specific foods contributing to the atherogenic potential of diet. Prev Med. 1993;22(2):203-18.

32. Fisberg RM, Morimoto JM, Slater B, Barros MB, Carandina L, Goldbaum M, et al. Dietary quality and associated factors among adults living in the state of Sao Paulo, Brazil. J Am Diet Assoc. 2006;106(12):2067-72.

33. Rafferty AP, Anderson JV, McGee HB, Miller CE. A healthy diet indicator: quantifying compliance with the dietary guidelines using the BRFSS. Prev Med. 2002;35(1):9-15.

34. Namayandeh S, Sadr S, Ansari Z, Rafiei M. A cross-sectional study of the prevalence of coronary artery disease traditional risk factors in Yazd urban population, Yazd healthy heart project. International Cardivascular Research Journal. 2011;5(1):7-13.

35. Schillinger D, Grumbach K, Piette J, Wang F, Osmond D, Daher C, et al. Association of health literacy with diabetes outcomes. JAMA. 2002;288(4):475-82.

36. de Lorgeril M, Salen P, Martin JL, Monjaud I, Delaye J, Mamelle $\mathrm{N}$. Mediterranean diet, traditional risk factors, and the rate of cardiovascular complications after myocardial infarction: final report of the Lyon Diet Heart Study. Circulation. 1999;99(6):779-85.

37. Chrysohoou C, Panagiotakos DB, Aggelopoulos P, Kastorini CM, Kehagia I, Pitsavos C, et al. The Mediterranean diet contributes to the preservation of left ventricular systolic function and to the long-term favorable prognosis of patients who have had an acute coronary event. Am J Clin Nutr. 2010;92(1):47-54.

38. Panagiotakos DB, Pitsavos C, Chrysohoou C, Skoumas I, Stefanadis C. Five-year incidence of cardiovascular disease and its predictors in Greece: the ATTICA study. Vasc Med. 2008;13(2):113-21.

39. Sofi F, Cesari F, Abbate R, Gensini GF, Casini A. Adherence to Mediterranean diet and health status: meta-analysis. $B M J$. 2008;337:a1344.

40. Bhupathiraju SN, Tucker KL. Coronary heart disease prevention: nutrients, foods, and dietary patterns. Clin Chim Acta. 2011;412(17-18):1493-514. 